\title{
DOBLE VÍNCULO LÉXICO EN ALGUNAS COLOCACIONES VERBONOMINALES*
}

\author{
Kazumi KOIKE
}

\section{OBJETIVO}

Aunque pueda parecer que existe un solo vínculo léxico en la colocación verbonominal suavizar el castigo, el vínculo que se establece entre suavizar y castigo, en realidad existe otro implícito, el que se presenta entre castigo y rigor o dureza: lo que se suaviza no es el castigo en sí, sino el rigor o la dureza del mismo. El significado de castigo implica cierto rigor o dureza, de ahí la adecuación de la combinación del sustantivo castigo con el verbo suavizar. La colocación suavizar el castigo (1a) podría parafrasearse por la expresión suavizar el rigor o la dureza del castigo (1b), en la que pueden verse con claridad los dos vínculos léxicos indicados:

(1a) suavizar el castigo

(1b) suavizar el rigor (o la dureza) del castigo

En la medida en que la verdadera base que selecciona el verbo no está explícitamente presente, puede decirse que la combinación verbonominal suavizar el castigo es una colocación elíptica ${ }^{1}$, donde el sustantivo castigo funciona como base de la colocación. En realidad, tal combinación compendia dos colocaciones: suavizar el castigo y suavizar el rigor (del castigo).

El objetivo del presente trabajo es llamar la atención sobre la presencia del doble vínculo léxico que existe en determinadas colocaciones verbonominales y analizar el proceso semántico que da origen a estas 



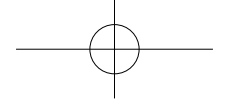

un ejemplo del segundo sería la combinación habitualizada aliviar la circulación de vehículos, donde, si bien el sustantivo circulación puede funcionar como base de la colocación, cabe suponer que, en realidad, esta estaría representada por el sustantivo densidad, que está implícito: aliviar la densidad de la circulación de vehículos. En este último caso existe, pues, un doble vínculo léxico o una doble colocación: aliviar la circulación y aliviar la densidad.

Llamamos colocaciones dobles al segundo tipo de colocaciones elípticas que presentan doble vínculo léxico. A continuación vamos a analizar los factores que hacen posible la ausencia de la verdadera base de la colocación, así como el significado de los verbos usados en las colocaciones dobles y el de los elementos implícitos en ellas.

\subsection{El significado del verbo}

El primer factor que favorece la ausencia de la verdadera base de una colocación doble es la presencia de un verbo. Creemos que la naturaleza verbonominal de la colocación es lo que determina el carácter doble del vínculo léxico, por cuanto el significado del verbo ayuda a recuperar la verdadera base.

Ahora bien, no todo tipo de verbo puede formar parte de una colocación doble. Los verbos de intensificación positiva o negativa tienden a aparecer en este tipo de colocaciones. Los verbos de intensificación positiva refuerzan las cualidades expresadas por los sustantivos que forman las colocaciones, mientras que los verbos de intensificación negativa (o de atenuación) reducen dichas cualidades. Pertenecen al primer grupo verbos como endurecer, fortalecer, recrudecer, extremar, acentuar, arreciar, estrechar, afianzar, agudizar, aumentar, etc., y, al segundo, verbos como suavizar, ablandar, dulcificar, debilitar, aliviar, aminorar, mitigar, atemperar, atenuar, apaciguar, reducir, aflojar, etc.

Veamos un ejemplo. La combinación de aliviar, de intensificación negativa, con el sustantivo circulación, constituye una colocación (2a). Este verbo establece un doble vínculo léxico: con el sustantivo implícito densidad (aliviar la densidad) y con el sustantivo circulación (aliviar la circulación) 

(2a) aliviar la circulación de vehículos en la zona (DCPEC, s. v. aliviar) (Ejemplo reproducido)

(2b) aliviar la (densidad de) circulación de vehículos en la zona (Ejemplo reproducido)

(2c) aliviar la (densa) circulación de vehículos en la zona

Al igual que aliviar la circulación, las combinaciones suavizar las relaciones y agilizar la burocracia admiten recuperar el lexema implícito en forma de adjetivo o de sustantivo. Como puede verse en los ejemplos siguientes, suavizar puede combinarse con los sintagmas las relaciones, las tensas relaciones o las tensiones, y agilizar, con los sintagmas la burocracia, la lentitud burocrática o la lenta burocracia:

(3) El príncipe Meyer se pregunta qué recuerdos de sí misma en aquella época conserva la archiduquesa de hoy, y si, en caso de que conserve algunos y se conceda la debilidad de rememorarlos, tienen algo que ver con la impotencia de Sofía para suavizar las relaciones con su nuera (CREA).

(4) Al ser consultado acerca de si esta captura podría ayudar a suavizar las tensas relaciones entre los dos vecinos, el Canciller consideró que "pudiera ser un paso positivo para la pacificación de la frontera (CREA).

(5) El responsable de la política exterior estadounidense utilizará Madrid como plataforma para suavizar las tensiones transatlánticas que han provocado espinosos asuntos como la ampliación de la OTAN y el conflicto yugoslavo (CREA).

(6) Los cambios [...] pueden agilizar el funcionamiento del departamento si se consigue agilizar la burocracia. [http://elpais.com/diario/1985 /04/27/cultura/483400802_850215.html]

(7) En esa tarea en la que se ha involucrado la iniciativa privada, según Marco Aurelio Pérez, las administraciones públicas tienen el objetivo de agilizar la lentitud burocrática [...]. [http://maspalomasactualidad. blogspot.jp/2012_07_14_archive.html] 
(8) La canciller apunta a agilizar la lenta burocracia germana para evitar costos y [...]. [http://www.frenteacano.com.ar/noticia/158780]

\section{ANÁLISIS SEMÁNTICO}

\subsection{El significado del sustantivo implícito}

Dado que los sustantivos y adjetivos implícitos en las colocaciones dobles están relacionados morfológicamente y poseen un mismo lexema, hacemos un análisis semántico de los sustantivos implícitos en el presente apartado.

Se ha observado que sustantivos deadjetivales como gravedad ( $<$ grave), dureza $(<$ duro), rigidez $(<$ rígido), tensión $(<$ tenso), densidad $(<$ denso) suelen ser elementos implícitos en las colocaciones dobles. Estos sustantivos expresan 'cualidades' propias del sustantivo explícito de la colocación y pueden combinarse con verbos de intensificación positiva y negativa. Resultan colocaciones dobles cuando estos verbos se vinculan directamente con el sustantivo explícito. Así, como la dureza es una cualidad aplicable a la crítica, el sustantivo dureza puede colocarse con verbos de intensificación positiva, como reforzar, o de intensificación negativa, como suavizar, aligerar, atenuar, mitigar o rebajar. El verbo suavizar, al combinarse directamente con crítica sin que medie el sustantivo dureza, se crea una colocación doble: suavizar la crítica. Este proceso puede representarse como sigue:

suavizar la dureza + la dureza de la crítica $>$ suavizar la dureza de la crítica $>$ suavizar la crítica

Lo mismo ocurre con aliviar el tráfico, colocación en la que el elemento implícito es el sustantivo densidad:

aliviar la densidad + la densidad del tráfico $>$ aliviar la densidad del tráfico $>$ aliviar el tráfico

Además, hay algunos sustantivos, como peso, rigor, efecto, etc., que, aunque no derivan del adjetivo, denotan una cualidad de otro sustantivo. Tales 
sustantivos pueden funcionar como elementos implícitos en las colocaciones dobles. Así, en las combinaciones aliviar/ aligerar la deuda y extremar las medidas están implícitos los sustantivos peso y rigor, respectivamente: aliviar/ aligerar (el peso de) la deuda, extremar (el rigor de) las medidas. Los ejemplos siguientes ilustran el proceso de formación de estas colocaciones dobles:

(9) Suecia dona 3.865 millones para aliviar la deuda de varios países pobres (CREA).

(10) El FMI y el BM estudiarán la posibilidad de que Nicaragua, al igual que Bolivia, se beneficien de su próxima decisión para aliviar el peso de la deuda de los países más pobres... (CREA).

(11) A nuestro criterio, Taiwan tendrá que extremar las medidas diplomáticas con los países amigos y [...] (CREA).

(12) [...] el Ministerio de Gobernación y la Dirección General de Seguridad [...] extremaron el rigor de las medidas sobre las defensas y pesos de los toros (CREA).

\subsection{De una colocación sustantivoadjetival a una colocación doble}

La colocación sustantivoadjetival desempeña un papel importante en la formación de una colocación doble.

Volvamos a analizar el proceso de formación de la colocación doble suavizar el castigo. Si el sustantivo castigo es compatible con suavizar, es porque castigo se coloca con el adjetivo duro con el sentido figurado. Dado que la dureza puede suavizarse, el sustantivo dureza se combina, a su vez, con suavizar, pero su presencia no es necesaria cuando suavizar se coloca con castigo. Detrás de la colocación suavizar el castigo existe un vínculo léxico de dureza con suavizar ${ }^{6}$.

suavizar la dureza + la dureza del castigo $(<$ un castigo duro $)>$ suavizar la dureza del castigo > suavizar el castigo 


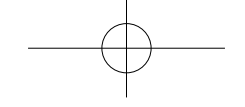

Muchas colocaciones dobles disponen implícitamente de su correspondiente colocación sustantivoadjetival, como es el caso de un castigo duro en suavizar el castigo.

Sustantivos como castigo, medida, disciplina, ataque, enfrentamiento, etc., que pueden combinarse con el adjetivo duro, pueden formar colocaciones dobles con verbos de intensificación negativa como los que aparecen en la tabla siguiente:

\begin{tabular}{|l|l|}
\hline \multicolumn{1}{|c|}{ Sustantivos } & \multicolumn{1}{|c|}{ Verbos de intensificación negativa } \\
\hline castigo & suavizar, ablandar(se), dulcificar, atenuar, aligerar, rebajar, aminorar \\
\hline medida & dulcificar \\
\hline disciplina & aflojar, relajar(se), distender(se) \\
\hline ataque & dulcificar, mitigar \\
\hline enfrentamiento & suavizar, mitigar, apaciguar \\
\hline corazón & ablandar(se) \\
\hline rasgo & ablandar(se), dulcificar \\
\hline
\end{tabular}

El ejemplo (13), en el que aparecen dos colocaciones (un castigo duro y aligerar un castigo) justifica el proceso de formación de la colocación doble aligerar el castigo:

(13) un castigo demasiado duro que había que pensar en aligerar progresivamente (DCPEC, s. v. aligerar).

\subsection{Antonimia en las colocaciones}

Los verbos de intensificación negativa suelen combinarse con las palabras que tienen el significado opuesto (antónimos). Así, el verbo suavizar y sus sinónimos tienden a colocarse con los sustantivos que designan dureza, rigidez o severidad. Entre suavizar y dureza o duro existe una relación de antonimia, aunque estas palabras no pertenecen a la misma categoría gramatical.

En las colocaciones dobles del tipo suavizar (la dureza d)el castigo/ el 


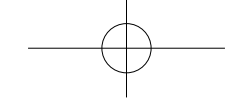

(duro) enfrentamiento, existe implícitamente este tipo de antonimia.

Hemos elaborado una lista de verbos con sus antónimos (adjetivos y sustantivos) correspondientes, junto con sus posibles colocaciones dobles:

\begin{tabular}{|c|c|c|}
\hline \multicolumn{2}{|c|}{ Antonimia } & \multirow{2}{*}{ Colocaciones } \\
\hline $\mathrm{V}(<\mathrm{A})$ & $\mathrm{A} / \mathrm{N}$ & \\
\hline ablandar(se) $(<$ blando $)$ & rígido / rigidez & $\begin{array}{l}\text { ablandar(se) su postura (rígida)/ } \\
\text { su actitud (rígida) }\end{array}$ \\
\hline ablandar(se) (<blando) & duro / dureza & ablandar(se) (la dureza d)el castigo \\
\hline agilizar (<ágil) & lento / lentitud & $\begin{array}{l}\text { agilizar la (lenta) burocracia / } \\
\text { el (lento) trámite }\end{array}$ \\
\hline aligerar (<ligero) & denso / densidad & $\begin{array}{l}\text { aligerar la (densa) agenda/ } \\
\text { la (densa) circulación }\end{array}$ \\
\hline aliviar (<leve) & $\begin{array}{l}\text { intenso / } \\
\text { intensidad }\end{array}$ & aliviar el dolor (intenso) / el (intenso) calor \\
\hline aliviar (<leve) & grave / gravedad & aliviar la (grave) crisis \\
\hline aflojar (<flojo) & riguroso & aflojar la (rigurosa) vigilancia \\
\hline
\end{tabular}

Cabe señalar, sin embargo, que no siempre tiene validez general la antonimia entre el verbo y el elemento implícito, si bien es cierto que los antónimos se atraen semánticamente. Hay casos en que la dureza no se suaviza ni se ablanda, sino que se aligera o se rebaja, como lo ilustran los ejemplos que siguen:

(14) Intentó en vano aligerar con alguna broma la extrema dureza de sus declaraciones (DCPEC, s. v. aligerar)

(15) Sería bueno que el PP e IU [...] rebajaran la dureza de sus críticas contra el felipismo. (CREA).

Como resultado del análisis, se ha observado que el sustantivo dureza es compatible no solo con ablandar(se), sino también con aligerar, atenuar, mitigar o rebajar (verbos de intensificación negativa) y con acentuar, reforzar 

observa en un tipo de colocaciones verbonominales a las que llamamos colocaciones dobles. A modo de conclusión, exponemos sintéticamente el posible proceso de formación de estas colocaciones y sus características semánticas:

(1) La colocación doble, que es un tipo de colocación elíptica, se forma con la elipsis de un elemento (implícito) que constituye la verdadera base: suavizar el castigo se forma a partir de suavizar la dureza del castigo mediante la elipsis del sustantivo dureza, o bien a partir de suavizar el duro castigo mediante la elipsis del adjetivo duro. El vínculo léxico entre castigo y duro / dureza, que puede apreciarse en los sintagmas nominales un duro castigo o la dureza del castigo, favorece la supresión de duro o dureza cuando castigo se combina con suavizar, verbo que, por su significado, puede, además, colocarse con el antónimo de su derivado nominal (suavidad).

(2) En muchas colocaciones dobles existe implícitamente una colocación sustantivoadjetival paralela, como ilustra el par un castigo duro / suavizar el castigo.

(3) Los elementos implícitos son aquellos adjetivos o sustantivos que denotan propiedades físicas relativas al tacto, la forma, el sabor, el peso, el movimiento, la fuerza, el aspecto, etc.

(4) Los sustantivos compatibles con los adjetivos que denotan dichas propiedades físicas tienden a formar colocaciones dobles con verbos de intensificación positiva o negativa.

(5) Una relación de antonimia irregular se observa entre el elemento implícito y el verbo; p. ej., entre duro y suavizar $(<$ suave) en la colocación doble suavizar el castigo. 


$<$ Resumen $>$

\section{Doble vínculo léxico en algunas colocaciones verbonominales}

\section{Kazumi KOIKE}

En el presente trabajo hemos señalado la presencia del doble vínculo léxico que existe en determinadas colocaciones verbonominales. Se trata de una colocación doble que se forma con la elipsis de un elemento (implícito) que constituye la verdadera base. Así, suavizar el castigo se ha formado a partir de suavizar la dureza del castigo mediante la elipsis del sustantivo dureza, o bien a partir de suavizar el duro castigo mediante la elipsis del adjetivo duro.

Hemos demostrado que ciertos adjetivos o sustantivos que denotan propiedades físicas relativas al tacto, la forma, el sabor, el peso, el movimiento, la fuerza y el aspecto desempeñan implícitamente un papel determinante en la selección del verbo de estas colocaciones.

Los sustantivos compatibles con los adjetivos que denotan dichas propiedades físicas tienden a formar colocaciones dobles con verbos de intensificación positiva o negativa.

Palabras clave: vínculo léxico, colocaciones léxicas, colocaciones verbonominales, adjetivos sinestéticos 